\title{
PENGARUH BUDAYA AUSTRONESIA PADA SITUS-SITUS DI KAWASAN KOKAS KABUPATEN FAKFAK PROVINSI PAPUA BARAT
}

\author{
(The Impact of Austronesian Culture on The Sites In The Kokas Area of The \\ Fakfak Regency of West Papua Province)
}

\section{Bau Mene}

Balai Arkeologi Papua.

Jl. Isele, Kampung Waena, Distrik Heram, Kota Jayapura, Papua 99358

Pos-el : baumene83@gmail.com

\begin{tabular}{l}
\multicolumn{1}{c}{ INFO ARTIKEL } \\
\hline Histori Artikel \\
Diterima : 13 Maret 2020 \\
Direvisi : 10 Juni 2020 \\
Disetujui : 23 Juni 2020 \\
\hline
\end{tabular}

Keywords:

Austronesian Culture, Kokas Region, Fakfak

\section{Kata kunci:}

Budaya Austronesia, Kawasan Kokas, Fakfak

\section{ABSTRACT}

Fakfak Regency is one of the regencies in West Papua Province that has quite a variety of archaeological data. The purpose of this paper is to provide a description of archeological remains in the Kokas region that characterize Austronesian culture. The method used in this research is the method of data collection which includes literature study, surveys on sites in the Kokas area and interviews. The results of research in several villages within the Kokas district area obtained data of rock paintings in the form of hand stencil, sun, anchors, red and yellow painting dots, the paintings are found on coral cliffs in Ugar Island and Arguni Island. Futhermore there was rockselters in which there are skulls, human bones, pottery fragments, foreign ceramic fragments, mollusk shells, and bone fragments.

\begin{abstract}
ABSTRAK
Kabupaten Fakfak adalah salah satu kabupaten di Provinsi Papua Barat yang menyimpan data arkeologis yang cukup beragam. Tujuan penulisan ini adalah untuk memberikan gambaran tinggalan arkeologi yang ada di kawasan Kokas yang mencirikan budaya Austronesia. Metode penelitian yang dilakukan dalam penulisan ini adalah survei dan analisis, teknik pengumpulan data melalui survei ke situs-situs yang ada di kawasan Kokas, studi pustaka dan wawancara. Hasil penelitian pada beberapa kampung yang berada dalam kawasan distrik Kokas diperoleh data lukisan - lukisan cadas berupa cap tangan,matahari, jangkar,titik- titik lukisan berwarna merah dan kuning, lukisanlukisan tersebut terdapat pada tebing-tebing karang di Pulau Ugar dan Pulau Arguni. Selain itu terdapat ceruk-ceruk yang didalamnya ditemukan tengkorak dan tulang-tulang manusia, fragmen gerabah, fragmen keramik asing, cangkang moluska, fragmen tulang.
\end{abstract}




\section{PENDAHULUAN}

Indonesia memegang peran

kunci dalam studi Austronesia. Dari

sudut geografi, Indonesia menduduki

posisi yang strategis mengingat

wilayahnya yang sangat luas dan

terletak di bagian tengah kawasan

diaspora austronesia. Lebih dari 80\%

penutur austronesia berdiam di

wilayah ini dengan berbagai ragam

budaya keberadaan kantong-kantong

penutur non Austronesia di Maluku,

Sunda kecil dan Papua sangat

penting untuk mengetahui proses

interaksi dengan kelompok

Austonesia (Simanjuntak, 2012: 6).

Munandar

menguraikan bahwa pada sekitar

tahun 3000-2500 BC, orang-orang

Austronesia mulai berlayar dari

pedalaman Cina selatan daerah

Yunnan menyeberangi lautan menuju

Taiwan dan Kepulauan Filipina.

Diaspora Austronesia berlangsung terus hingga tahun 2500 SM mereka mulai memasuki Sulawesi, Kalimantan dan pulau-pulau lain di sekitarnya. Dalam sekitar tahun 2000 SM kemungkinan mereka telah mencapai Maluku dan Papua. Dalam masa yang sama itu pula orang-orang Austronesia dari daratan Asia Tenggara berangsur-angsur memasuki Semenanjung Malaysia dan pulau-pulau bagian barat Indonesia. Migrasi ke arah pulaupulau di Pasifik berlanjut terus hingga sekitar tahun 500 SM hingga awal dihitungnya tarikh Masehi.

Kira-kira sejak 3500 tahun silam, Papua telah menjadi jalur perlintasan kelompok penutur bahasa Austronesia yang menghuni hampir seluruh bagian kepulauan Nusantara yang kehadirannya telah menandai kegiatan ekonomi diantaranya melalui produksi gerabah. Jejak arkeologis menunjukkan bahwa orang Austronesia telah melintasi pulau-pulau di Asia Tenggara menuju bagian utara Papua dan keluar menuju ke Kepulauan Melanesia, Polinesia dan Mikronesia serta mencapai Selandia Baru melalui pesisir Pantai Papua. Dengan posisi geografisnya, Papua selain menyerap budaya Melanesia dari Pasifik, juga mendapat pengaruh dari penutur Austronesia. Sisa-sisa interaksi yang menandai kehadiran 
budaya Austronesia di Papua serta tradisi prasejarah berlanjut masih dapat ditemukan bukti-buktinya sampai sekarang (Amal, 2010: 3).

Kabupaten

Fakfak

merupakan salah satu kabupaten yang berada di Provinsi Papua Barat, wilayah ini menyimpan data arkeologi yang cukup beragam, terletak antara $131^{\circ} 30-138^{\circ} 40 \mathrm{BT}$ dan $2^{\circ} 25-4^{\circ} 00 \mathrm{LS}$, dengan luas wilayah $14.320 \quad \mathrm{Km}^{2}$. Secara administratif berbatasan langsung dengan Kabupaten Teluk Bintuni di sebelah utara, Laut Arafura dan Kabupaten Kaimana di sebelah selatan, Laut Seram dan Teluk Berau di sebelah barat, dan Kabupaten Kaimana di sebelah timur (Tim Peneliti Fakfak, 2018: 1)

Tulisan ini akan mengeksplorasi tinggalan arkeologi yang ada di kawasan Distrik Kokas yang diperkirakan tinggalan tersebut mendapat pengaruh budaya Austronesia. Ciri budaya Austronesia menurut Simanjuntak adalah dikenalnya budaya pertanian, teknologi pelayaran yang lebih maju, teknologi tembikar polos/slip merah, domestikasi hewan dan tanaman. Dibidang teknologi menghasilkan produk seperti peralatan dan perhiasan litik (beliung, kapak gelang dan lain-lain) (Simanjuntak, 2011: 4-18)

Menurut Tanudirdjo artefak yang dapat dianggap dapat menunjukkan interaksi budaya penutur Austronesia dan masyarakat Melanesia sekitar 3500 tahun yang lalu diantaranya gerabah, beliung persegi, pahat batu poles, batu penumbuk biji, artefak kerang conus, kail kerang, rumah berdenah persegi, perkampungan terbuka, tradisi kunyah pinang dan pelihara ternak babi, ayam serta anjing. Diantara sejumlah budaya bendawi itu, salah satu artefak yang menonjol adalah gerabah, selain itu seni cadas (rock art) merupakan pengaruh budaya Austronesia (Tanudirjo, 2011: 25).

Lukisan cadas yang terdapat di kawasan Kokas berupa fauna air laut seperti ikan, cumi-cumi, teripang, dan buaya, geometris (lingkaran, garis berpotongan,titiktitik, segi empat, matahari).benda budaya (bumerang, mata panah, kapak, tugal, wadah, jaring, dayung), garis berbentuk V, garis silang, lukisan abstrak, fauna darat (burung, 
kadal), gambar berukir (Tim penelitian Fakfak, 2009: 40).

Dalam perspektif waktu, studi Austronesia melingkupi rentang sekitar 4000 tahun terhitung sejak kemunculan penutur Austronesia awal hingga sekarang. Berpatokan pada model Peristiwa Besar (Big Events), studi Austronesia dapat dibagi paling tidak dalam tiga kelompok berdasarkan periode perkembangan budayanya. Ketiga kelompok studi dan periodisasi Austronesia tersebut adalah:

1. Austronesia Prasejarah : dimulai sejak kehadiran penutur Austronesia awal di kepulauan hingga sekitar 2000 BP. Budaya penanda pada periode ini adalah neolitik dengan inovasi-inovasi yang membawa perubahan besar di berbagai bidang kehidupan,

2. Austronesia Protosejarah: Berkembang di sekitar 2000 BPabad IV/V Masehi ditandai dengan kehidupan masyarakat yang makin kompleks, seiring dengan kemajuan di bidang pelayaran dan perdagangan regional-global. Budaya penanda pada periode ini adalah praktek penguburan tempayan yang merupakan tradisi berlanjut dari zama prasejarah (neolitik), bendabenda logam pengaruh budaya Dongson, dan megalitik yang juga pengaruh budaya luar.

3. Austronesia Masa kini; cakupan waktu terhitung sejak kemerdekaan hingga sekarang, dicirikan oleh lepasnya masyarakat Indonesia dari dominasi budaya asing, hingga dimulainya proses pembentukan budaya nasional yang merupakan campuran tradisi-tradisi budaya asli dan budaya modern. Dalam konteks ini studi Austronesia lebih difokuskan pada tradisitradisi budaya asli (Simanjuntak, 2011: 8-9).

Jauh sebelum kedatangan orang Austronesia sekitar sebelum 10.000 tahun yang lalu sebenarnya penduduk asli Papua yang mendiami New Guinea telah terlebih dahulu mencapai pulau-pulau besar maupun pulau-pulau kecil yang berada dekat dengan daratan. Pulau-pulau tersebut mencakup Britania Baru, Irlandia Baru 
dan sebagian besar pulau di Kepulauan Solomon. Wilayah sebelah utara Solomon bahkan telah mereka jelajahi lebih dahulu sekitar 30.000 tahun yang lalu. Tetapi mereka telah melanjutkan penjelajahan mereka lebih jauh lagi, kemungkinan besar karena lautan yang harus diarungi untuk mencapai rangkaian pulau berikutnya (yaitu Vanuatu dan Fiji) yang teramat luas. Pada akhirnya, pulau-pulau yang tak bisa mereka taklukkan oleh pendatang baru yaitu orang Austronesia. Para pendatang baru ini bahkan bisa mendiami pulaupulau sepanjang Samudra Pasifik (Muller, 2008: 49)

Dari penelitian yang telah dilakukan oleh Balai Arkeologi Papua pada beberapa situs yang masuk dalam kawasan distrik Kokas yang terdapat di Pulau Ugar (Kampung Ugar dan Tebing Sarfa) dan Pulau Arguni (situs tebing Mampoga, Gua Dudumunir, dan Tebing) diperkirakan bahwa wilayah tersebut telah mendapat pengaruh budaya Austronesia. Hal ini terlihat dari tinggalan arkeologi yang ditemukan pada situs-situs di Pulau

Arguni, Pulau Ugar dan sekitarnya. Dari latar belakang tersebut di atas permasalahan yang akan diungkapkan adalah Bagaimana bentuk pengaruh budaya Austronesia yang ditemukan dalam kawasan Distrik Kokas .

\section{METODE PENELITIAN}

Metode penelitian yang digunakan dalam penulisan ini adalah survei dan analisis. Teknik pengumpulan data dilakukan melalui studi pustaka, survei dan wawancara. Studi pustaka dilakukan untuk mengumpulkan data-data atau literatur yang berkaitan dengan objek kajian. Survei dilakukan untuk mengetahui adanya tinggalan arkeologis ataupun untuk menemukan tinggalan arkeologis.

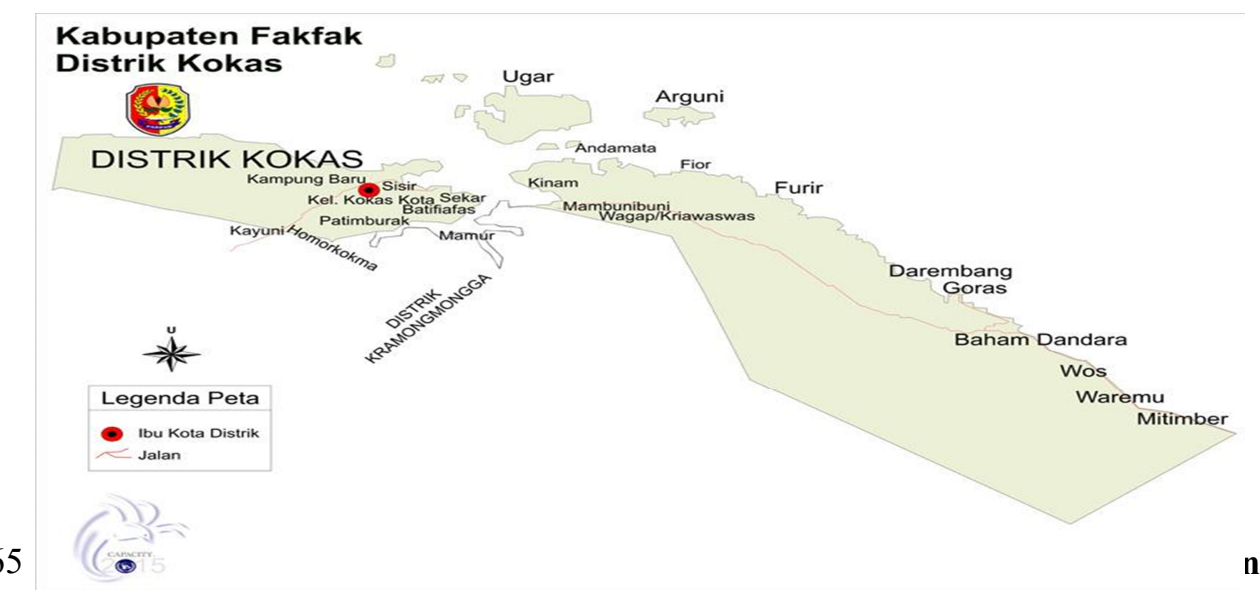

Peta Distrik Kokas, Sumber https://Fakfakkab.bps.go.id 
HASIL DAN PEMBAHASAN

Penelitian di Kabupaten Fakfak dilakukan pada tanggal 25 Mei sampai 4 Juni tahun 2015. Penelitian dilakukan dalam kawasan distrik Kokas yaitu di Pulau Arguni, Pulau Ugar, dan beberapa tebing-tebing yang masuk dalam kawasan distrik Kokas

\section{Pulau Arguni}

Pulau Arguni terletak di kampung Arguni distrik Arguni. Perjalanan menuju Pulau Arguni kampung arguni menggunakan kendaraan roda empat dari ibu kota Kabupaten Fakfak menuju ke Distrik Kokas, dari Kokas perjalanan dilanjutkan dengan menggunakan perahu speedboat ke Kampung Arguni. Akses ke situs dari Kampung Arguni menggunakan ransportasi perahu, jika air laut surut dapat ditempuh dengan berjalan kaki menyusuri tepian pantai.
Di Pulau Arguni survei dilakukan pada Gua Dudumunir dan melakukan pendataan pada beberapa tebing karang yang terdapat lukisan dinding, serta beberapa ceruk karang yang terdapat tengkorak dan tulangtulang manusia, rumah tinggal raja, makam keluarga raja. Gua Dudumunir terletak pada koordinat $\mathrm{S}$ : $02^{0} 39^{\prime}$ 17. 4". dan E: $132^{0} 32^{\prime}$ 55.1". Gua menghadap arah timur, lebar mulut gua 12 meter, panjang gua 30 meter. Kondisi lantai gua kering dan basah, bentuk lantai gua datar pada bagian langit-langit gua terdapat banyak coretan-coretan. Untuk mencapai gua sangat mudah karena posisi gua dekat dengan bibir pantai. Posisi gua sekitar 15 meter dari bibir pantai. Tanaman yang ada di sekitar gua pohon kelapa, pandan hutan. Hasil survei pada permukaan gua ditemukan fragmen gerabah,
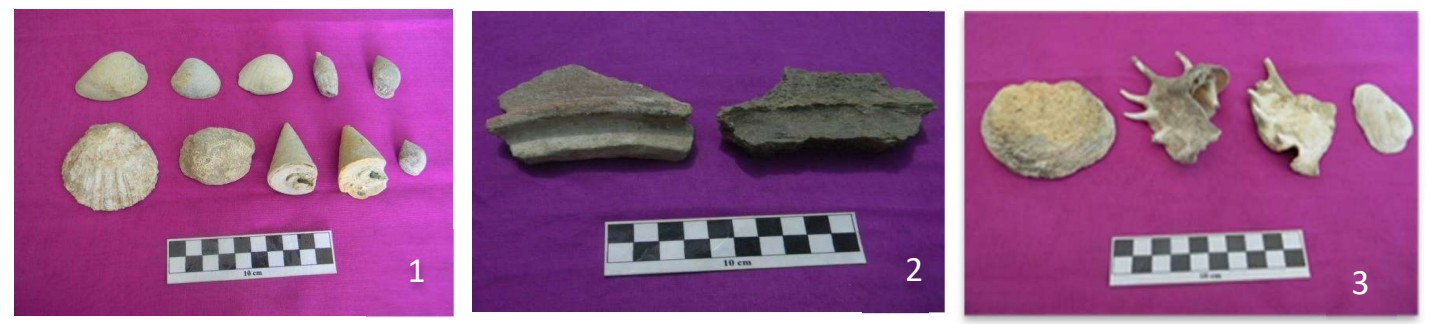

Gambar: 1 dan 3. cangkang kerang Gua Dudumunir, Gambar 2. fragmen gerabah (Sumber Balai Arkeologi Papua). 
dan cangkang kerang, fragmen Pelvis

(tulang paha manusia, fragmen

Costae Pisces (fragmen tulang rusuk

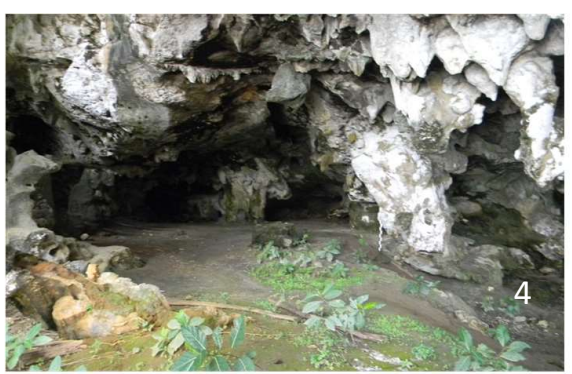

Gambar 4. Foto Kondisi Gua Dudumunir (Sumber Balai Arkeologi Papua)

paus). Berdasarkan identifikasi taponomi tulang dan hasil komparasi dengan anatomi struktur tulang ikan paus. Selain itu ditemukan juga lukisan dinding pada bagian dalam gua. Lukisan berwarna hitam. Lukian sudah tidak dapat diidentifikasi bentuknya selain karena lukisan tersebut sudah pudar, banyak terdapat coretan-coretan akibat vandalisme.
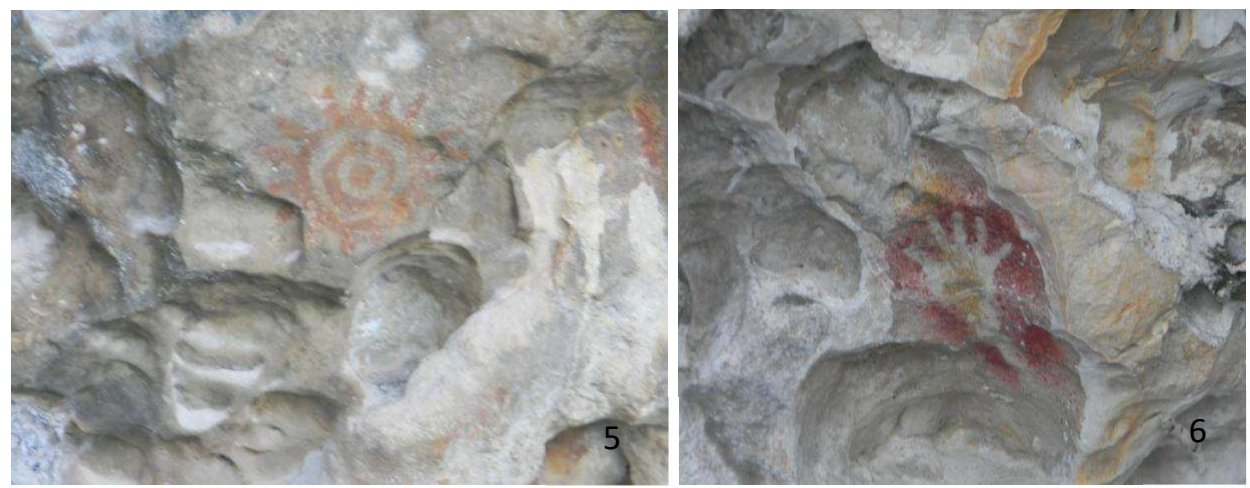

Gambar 5 dan 6 lukisan cap tangan tebing Mampoga

(Sumber Balai Arkeologi Papua)

\section{Tebing Mampoga}

Tebing Mampoga terletak pada koordinat S: $02^{0} 39^{\prime} 17.4$ " dan E: $132^{0} \quad 33^{\prime}$ 43.1". Tebing ini berbatasan dengan sebelah barat Kampung Arguni, sebelah barat Tanjung Fameta, sebelah selatan Kampung Fior, sebelah Utara Teluk Berau. Pada tebing ini ditemukan lukisan telapak tangan berukuran kecil dan telapak tangan berukuran besar ikan. Titik-titik, jangkar, matahari. Lukisan berwarna merah dan kuning. Selaim lukisan ditemukan banyak tulang- tulang dan tengkorak manusia. Menurut masyarakat setempat tulang-tulang dan tengkorak itu adalah tulangtulang dan tengkorak manusia yang dibantai pada saat perang suku / Hongi. 


\section{Tebing Risato}

Tebing Risato terletak pada koordinat S: $02^{0,} 38$ ' 58.7" dan E: $132^{0} 33^{\prime} 47.2^{\prime}$. lukisan cadas yang terdapat pada tebing ini adalah lukisan telapak tangan, ikan, lukisan abstrak. Warna lukisan merah dan kuning.

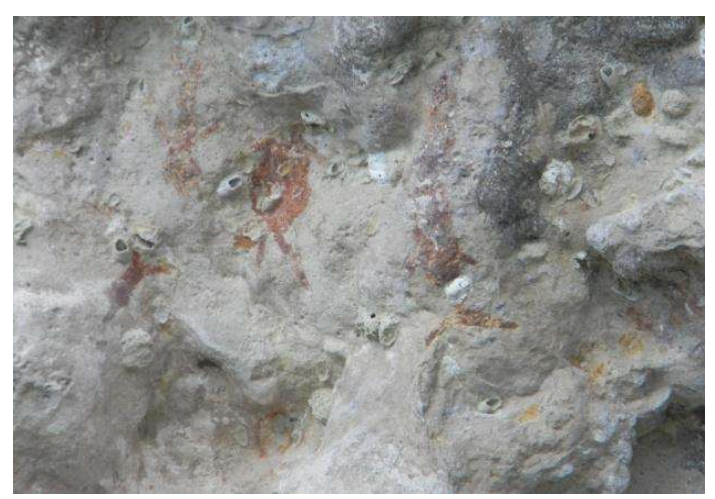

Gambar 7. Lukisan Tebing Risato ( Sumber. Balai Arkeologi Papua)

\section{Pulau Ugar}

Secara astronomis Pulau Ugar terletak pada S: $02^{0} 38^{\prime} 13.9^{\prime \prime}$ dan E: 1320 26' 44.4". Pulau ini masuk dalam wilayah Distrik Kokas. Survei di Kampung Ugar ditemukan fragmmen gerabah, cangkang kerang dan fragmen keramik. Selain temuan tersebut ditemukan lukisan yang terdapat pada tebing Sarfa.

Tebing Sarfa terletak pada koordinat : S : $02^{0} 37^{\prime} 31.8^{\prime \prime}$ dan E : $132^{0}$ 27' 56.9”'. Pada tebing ini terdapat lukisan cap tangan warna merah dan lukisan abstrak. Lukisan cap tangan ada yang berukuran besar dan kecil. Keletakan lukisan sekitar 7- 8 ,meter di atas permukaan air laut.

Pada kira-kira 2000 SM, orang Melayu- Polinesia Tengah Timur telah meluaskan penghuniannya hingga ke Timor melalui Maluku. Keterampilan dan teknik berlayar sudah lebih maju pada waktu itu, seperti jelas terlihat dari penghunian Oceania selanjutnya. Penghunian wilayah pesisir yang dapat dilakukan dengan mudah dan cepat rupanya lebih diminati daripada penghunian wilayah pedalaman yang lebih membutuhkan tenaga, dan lagi dibeberapa tempat sudah dihuni oleh
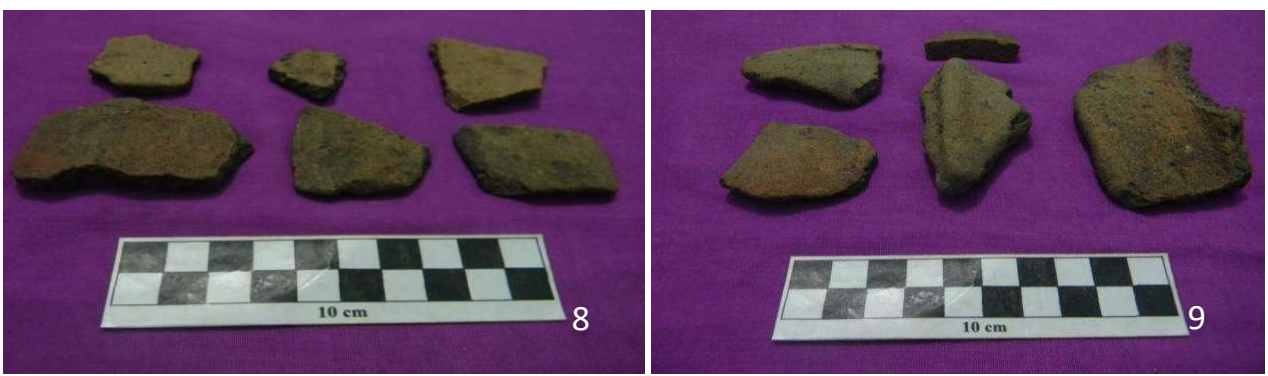

Gambar 8 dan 9. Temuan fragmen gerabah di Pulau Ugar (Sumber. Balai Arkeologi Papua) 
penduduk lain yang mungkin tidak menyukai mereka. Pertanian bijibijian menjadi kurang penting di Indonesia bagian timur, dan para pemukim Austronesia di Oceania mendasarkan ekonomi mereka semata-mata pada umbi-umbian, pohon buah, dan tanaman pangan bertunas lainnya (Bellwood, 2000: 353).

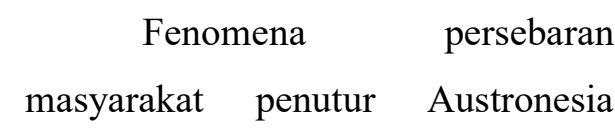
yang menjangkau Lautan Pasifik merupakan fenomena yang sangat mengagumkan. Banyak pakar menganggap, salah satunya Hendrik Kern, bahwa diaspora Austronesia terjadi karena tekanan penduduk dari kelompok masyarakat yang mendiami suatu pantai daerah tropis. Jejak arkeologis menunjukkan bahwa orang Austronesia telah melintasi pulau-pulau di Asia Tenggara menuju bagian utara Papua dan keluar menuju ke Kepulauan Melanesia (mela=hitam), Polinesia dan Mikronesia serta mencapai Selandia Baru melalui pesisir pantai Papua (Amal, 2010: 3).

Dengan posisi geografisnya, Papua selain menyerap budaya Melanesia dari Pasifik, juga mendapat pengaruh dari Austonesia. Sisa-sisa interaksi yang menandai kehadiran budaya Austronesia dan Melanesia di Papua serta tradisi prasejarah berlanjut masih dapat ditemukan bukti-bukti sampai sekarang. Di Papua, pengaruh Austronesia menapak di wilayah Kepala Burung (Raja Ampat: Kaimana: Fakfak, Teluk Bintuni) pesisir Pantai Utara, Pulau Biak dan Yapen. (Mahmud, 2011: 49-50)

Pengaruh Austronesia di wilayah Kepala Burung ditemukan lukisan cadas, di Manokwari (Pulau Mansinam) Kampung Lama (Pulau Cag) di Biak ditemukan terompet dan gelang kerang serta di bagian Jayapura (terutama Danau Sentani) dan di Biak ditemukan situs-situs yang mengandung gerabah polos merah.

Menurut Mahmud (2011), unsur budaya Austronesia di Papua, berupa gerabah, beliung persegi, pahat batu poles, batu penumbuk biji,artefak kerang conus rumah berdenah persegi, dan perkampungan terbuka serta domestikasi hewan (anjing, babi, ayam) dan tradisi mengunyah pinang yang nyata sampai sekarang. 
Kebudayaan dan teknologi

orang Austronesia ini sudah sangat maju. Mereka telah menjinakkan berbagai jenis hewan (ayam, anjing dan babi) serta membiakkan tanaman import yang bermanfaat. Perkakas yang mereka pergunakan sudah lebih baik. Organisasi kemasyarakatannya sudah terstruktur dengan sstem hirarki dengan bentuk kepemimpinan yang dijabat secara turun temurun. Dengan keahliannya, mereka juga mampu menghasilkan karya berupa ornamen-ornamen dan perkakas dengan bahan kulit kerang. Ornamen atau alat-alat berbahan kerang yang mereka buat termasuk beliung, manik-manik, mata kail, gelang tangan dan terompet (Muller, 2008: 53 dalam Suroto, 2010: 35).

Bukti pengaruh budaya Austronesia di kawasan Kokas dapat dilihat dari adanya lukisan dinding yang tersebar di tebing-tebing yang terdapat diatas permukaan laut sepanjang pantai selatan Teluk Berau yaitu antara Goras dan Kokas dan pada dinding-dinding ceruk dan tebing serta pada gua-gua yang terdapat pada beberapa pulau yang terdapat di perairan daerah ini seperti Pulau Ugar dan Arguni.

Lukisan dinding atau biasa disebut lukisan cadas merupakan data arkeologi yang dapat memberikan gambaran tentang kehidupan masa lampau. Bentukbentuk lukisan yang ditemukan pada saat penelitian berlangsung adalah telapak tangan berukuran kecil, telapak tangan berukuran besar, ikan, matahari, titik-titik, jangkar dan lukisan abstrak. Warna lukisan merah, kuning, hitam pada umumnya terletak kurang lebih 7 sampai 8 meter diatas permukaan laut. Lukisan- lukisan tersebut merupakan ekspresi seni yang dirasakan, dilihat dan dialami yang kemudian dituangkan dalam bentuk lukisan dengan memanfaatkan tebing-tebing karang. Adapun bentuk-bentuk lukisan yang ditemukan di daerah ini umumnya berupa gambar telapak tangan manusia, telapak kaki manusia, fauna, matahari, dan lain sebagainya (Heekeren 1972; Tim Peneliti Fakfak, 2009: 3).

$$
\text { Lukisan-lukisan yang }
$$

ditampilkan ada yang berkelompok, 
individu bahkan ada yang tumpah tindih Yang menjadi obyek gambarnya adalah apa yang dilihat pada lingkungan sekitar. Keberadaan lukisan-lukisan itu ada yang berkaitan dengan benda-benda di cakrawala yaitu matahari adapula yang berkaitan dengan binatang laut yaitu ikan lukisan tersebut mengandung makna sebagai mata pencaharian. Kemungkinan penggambaran motif ikan adalah karena ikan adalah binatang yang banyak dikonsumsi dan sebagai sumber mata pencaharian mereka. Bentuk-bentuk yang digambarkan mencerminkan keadaan dan kegiatan masyarakat pendukungnya seperti misalnya kegiatan berburu, menari, berperang, dan bahkan kegiatan keagamaan (Arifin, 1992: 1)

Selain merupakan ekspresi seni kemungkinan lukisan-lukisan tersebut juga mengandung makna sebagai penolak bala/bahaya misalnya lukisan cap tangan. Kehadiran lukisan dinding pada situs-situs di kawasan Kokas diperkirakan adalah pengaruh budaya Austronesia seperti halnya lukisanlukisan dinding yang terdapat di kawasan ditemukan di Raja Ampat (pulau Waigeo, Misool) dan Kaimana (Kawasan Kampung Maimai dan Teluk Triton).

\section{Ciri budaya Austronesia} lainnya yang tampak berupa organisasi kemasyarakatannya terstruktur dengan sistem hirarki dimana para pemimpinnya dijabat secara turun temurun. Hal ini terlihat pada masyarakat yang tinggal di Fakfak, Raja Ampat, Teluk Youtefa (Tobati, Enggros, Nafri, Kayu Batu) Waena dan Sentani. Ciri Austronesia lainnya adalah temuan fragmen gerabah pada situs-situs dalam kawasan Distrik Kokas. Fragmen gerabah ditemukan di Gua Dudumunir, Pulau Ugar, Gua Sosoraweru. Diperkirakan tradisi pembuatan gerabah di Papua khususnya pada situs-situs di kawasan Distrik Kokas dibawa oleh orang Austronesia. Tradisi pembuatan gerabah tidak dikenal dalam kawasan Distrik Kokas bahkan bahan untuk pembuatan gerabah tidak ditemukan.

Pengaruh budaya Austronesia yang lain nampak di Pulau Ugar dan Arguni yaitu dikenalnya tradisi mengunyah 
pinang. Kebiasaan mengunyah pinang dikenal dalam masyarakat Papua, baik masyarakat yang berdiam di pesisir pantai maupun masyarakat yang tinggal di pedalaman. Tradisi mengunyah pinang ini diwariskan secara turun temurun oleh nenek moyang. Tradisi mengunyah pinang dikenal hampir di seluruh suku yang ada di Indonesia diantaranya Sumatera, Jawa, Sulawesi, Kalimantan, Maluku dan Papua (Mene; 2013: 32).

Tradisi makan pinang di Papua dapat dijumpai di wilayah pesisir yaitu Sorong, Kaimana, Fakfak, Biak, Manokwari, Serui, Jayapura, Sarmi, Mamberamo. Tradisi ini berkembang hingga ke daerah pedalaman. Tanaman pinang dibudidayakan di pekarangan rumah dan kebun. Kebiasaan mengunyah pinang dimaksudkan sebagai penyedap mulut, pembangkit semangat, atau hanya sekedar sebagai hidangan tamu (Mene, 2013: 38).

Makan sirih pinang bisa dijadikan sebagai media untuk berkenalan, apabila bertemu seseorang yang belum dikenal untuk memulai perkenalan dengan orang tersebut maka orang tersebut ditawari makan pinang dengan makan pinang bersama akhirnya berkenalan, ngobrol dengan perkenalan tersebut akan timbul rasa persaudaraan. Selain itu makan pinang dapat membangkitkan rasa percaya diri, menguatkan gigi dan menghilangkan bau mulut (wawancara, Faiyo Klementin).

Pada masyarakat Papua khususnya yang berdiam di pesisir kebiasaan makan pinang dilakukan pada saat lamaran dan acara perkawinan. Pada saat acara lamaran dilakukan keluarga pihak laki-laki mengantar barang hantaran berupa kapak batu, manik-manik disertai sirih pinang. Tujuan penyertaan sirih pinang untuk disuguhkan kepada para tamu yang datang namun biasanya keluarga pihak perempuan juga menyiapkan sendiri sirih pinang untuk dimakan bersama pada saat acara lamaran berlangsung. Acara makan sirih pinang ini dimulai sebelum memulai pembicaraan dan proses lamaran berlangsung. Acara 
makan sirih pinang dimulai sebelum memulai pembicaraan dan proses lamaran berlangsung. Setelah selesai proses lamaran dan disepakati jadwal pernikahan keluarga pihak laki-laki pulang kerumah untuk mempersiapkan barang-barang hantaran pada saat pernikahan nanti

\section{PENUTUP}

Berdasarkan hasil penelitian yang telah dilakukan pada beberapa situs yang ada dalam kawasan Distrik Kokas Kabupaen Fakfak diantaranya Pulau Arguni yaitu Situs Gua Dudumunir, Situs tebing Risato, tebing Mampoga, situs tebing-tebing yang terdapat di Pulau Ugar maka kesimpulan yang dapat diambil bahwa kawasan distrik Kokas kemungkinan telah mendapat pengaruh budaya Austronesia. Buktibukti tersebut dapat kita lihat dari adanya temuan lukisan dinding pada tebing-tebing karang yang diperkirakan lukisan-lukisan tersebut adalah pengaruh budaya Austronesia. Temuan fragmen gerabah pada gua Dudumunir dan Pulau Ugar, Sistem organisasi kemasyarakatan yang terstruktur dengan sistem hirarki dimana para pemimpinnya dijabat secara turun temurun dan masih berlangsung sampai saat ini, dan adanya tradisi makan pinang dalam masyarakat.

\section{DAFTAR PUSTAKA}

Amal, M. Adnan. 2010. Kepulauan Rempah-Rempah Perjalanan Sejarah Maluku Utara 1250-1950. cet.1 Jakarta. Kepustakaan Populer Gramedia

Arifin, Karina. 1992. Lukisan Batu Karang di Indonesia.Departemen Pendidikan dan Kebudayaan. Depok: Lembaga Penelitian Universitas Indonesia.

Bellwood, Peter. 2000. Prasejarah Kepulauan Indo-Malaya edisi revisi. Jakarta: Gramedia. Pustaka Utama.

Mahmud, Irfan. 2011. "Jejak Austronesia, Melanesia dan Tradisi Prasejarah Berlanjut di Papua" dalam Austronesia dan Melanesia di Nusantara. Balai Arkeologi Jayapura.

Mene, Bau. 2013. "Tradisi Menginang di Papua". dalam: Kebudayaan Papua. Balai Arkeologi Jayapura. 
Muller, Kal. 2008. Mengenal Papua. Daisy World Books.

Munandar Aris, Agus. 2012 . Kebudayaan Austronesia Sebagai Akar Kebudayaan Nusantara Ornamen pada Nekara dan Artefak Perunggu Lainnya. Majalah Arkeologi Indonesia.

Simanjuntak, Harry, Truman. 2011. "Jejak Austronesia, Melanesia dan Tradisi Prasejarah Berlanjut di Papua" dalam Austronesia dan Melanesia. Balai Arkeologi Jayapura.

Suroto, Hari. 2010 . Prasejarah Papua. Denpasar: Udayana University Press.

Suroto, Hari. 2011. "Budaya Austronesia di Papua" dalam Austronesia dan Melanesia di Nusantara. Balai Arkeologi Jayapura.

Tanudirdjo, Aris Daud. "Austronesia dan Melanesia di Nusantara" Austronesia dan Melanesia di Nusantara. Balai Arkeologi Jayapura.

Tim Peneliti. 2009. "Penelitian Lukisan Dinding di Kawasan Kokas Fakfak" Laporan Penelitian Balai Arkeologi Jayapura. Belum terbit.

Tim Peneliti. 2015. "Penelitian Eksplorasi Arkeologi di Kabupaten Fakfak" Laporan Penelitian Balai Arkeologi Jayapura. Belum terbit.

Tim Peneliti. 2018. "Okupasi Hunian Prasejarah di Kawasan Teluk Berau Kabupaten Fakfak” Laporan Penelitian Balai Arkeologi Papua. Belum Terbit. 